\title{
Further Hospital Art Development of Masking Tape Using Thin Film Sheet
}

\author{
Kei TANAKA ${ }^{1}$, Shinji NAGAHIRO ${ }^{2,3,4}$, Hiroshi BANDO ${ }^{2,5}$ \\ ${ }^{1}$ Division of Integrated Arts and Social Sciences, Graduate School of Technology, Industrial and Social Sciences, Tokushima, \\ Japan \\ ${ }^{2}$ Shuseikai Medical Corporation, Yoshinogawa Hospital, Tokushima, Japan \\ ${ }^{3}$ Emeritus Professor, Department of Neurosurgery, Tokushima University, Tokushima, Japan \\ ${ }^{4}$ Former Director of Tokushima University Hospital, Tokushima, Japan \\ ${ }^{5}$ Medical Research/Tokushima University, Tokushima, Japan
}

Corresponding Author: Hiroshi BANDO, MD, PhD, FACP ${ }^{\text {ORCID iD }}$

Address: Tokushima University /Medical Research, Nakashowa 1-61, Tokushima 770-0943, Japan; Email:pianomed@bronze.ocn.ne.jp

Received date: 13 December 2021; Accepted date: 24 December 2021; Published date: 30 December 2021

Citation: Tanaka K, Nagahiro S, Bando H. Further Hospital Art Development of Masking Tape Using Thin Film Sheet. Asp Biomed Clin Case Rep. 2021 Dec 30;4(3):195-98.

Copyright (C) 2021 Tanaka K, Nagahiro S, Bando H. This is an open-access article distributed under the Creative Commons Attribution License, which permits unrestricted use, distribution, and reproduction in any medium provided the original work is properly cited.

\section{Abstract}

The authors and collaborators have continued practice of hospital art in the university and community hospitals and various research with experts. The material for hospital art is masking tape which is easily made and attached for everyone. Formerly, we have conducted artwork in front of the wall, which took a long time. Currently, we have tried to take the most advantage of the thin-film sheet. Our staff can prepare artwork with a size of $20 \mathrm{~cm}$ square in advance. Many square parts with double-sided attachment tape can be gathered together, which is completed and useful in a short time.

\section{Keywords}

Hospital Art, Masking Tape, Film Sheet, Art Work, Japan

In actual medical practice, many patients have aspired to adequate circumstances where relaxing space and time can be felt [1]. Among them, the necessity and effectiveness of hospital art have been reported and gradually known broadly [2]. The authors' group has been involved in hospital art and development so far [3].

The material used in the hospital art is masking tape [4]. This kind of work seems to be easy to perform, and there is an advantage that many people can participate in the work together happily without difficulties [5]. Clinical effects of masking tape were also found for daily activities of the elderly [6]. Artmaking activity in the hospital program provides positive benefits such as mindfulness and self-efficacy [7]. Our activity was initiated at a national university hospital in Japan for the psychological comfort of patients, families, and workers. Subsequently, our activity has developed in other public hospitals and general hospitals, and has contributed more for patients, hospitals and related societies in recent years [5].

Consequently, coronavirus disease-2019 (Covid-19) pandemic was found during 2020-2021. The degree of 
pandemic and various influences in Japan was less than those of other countries [8]. Our activities for hospital arts were interrupted by the Covid-19 pandemic. Almost all hospitals were forced to cut off all contact with the outside world and stopped accepting volunteers. On the other hand, medical staff who were too tense to relax and hospitalized patients who could not see their families and friends were under a lot of stress [9]. There was a need for an idea to ease their minds in the hospital. Minami Hospital, located in a small town in the southern part of Tokushima Prefecture, asked us to create a piece of hospital art that would break through this suffocating situation.

Then, we thought about how we could introduce artworks into a hospital while minimizing the risk of infection [10]. The problem is that our work in the field takes a long time. We have been making wall paintings in the corridors and stairways of the hospital by cutting various masking tapes with scissors or tearing them with our fingers and sticking them on the walls [5]. This process would take days or weeks, so we could not plan our production under the progressing pandemic.

Therefore, the authors and collaborators have considered a possible solution. In other words, instead of working just in front of the wall, it is possible to prepare in advance. Beforehand, to prepare the work to a certain extent, it will save time. A good idea for a solution would be to use a thin transparent film sheet. This material has been often used for wrapping bouquets and on cakes and lunch boxes. Masking tape can be set and attached to the film sheet in advance (Fig-1). Furthermore, we also tried to utilize the plaster sheet, which is called stucco or mortar, made of calcium hydroxide [11]. It has also an antibacterial and antiviral effect, and the back surface can be attached like double-sided tape. In this way, a lot of square parts with a size of about $20 \mathrm{~cm} \times 20 \mathrm{~cm}$ can be prepared, and the staff can bring them to the working place and install them in a short time (Fig-2).

The author's group originally conceived of this method during a workshop with elderly patients [6]. It

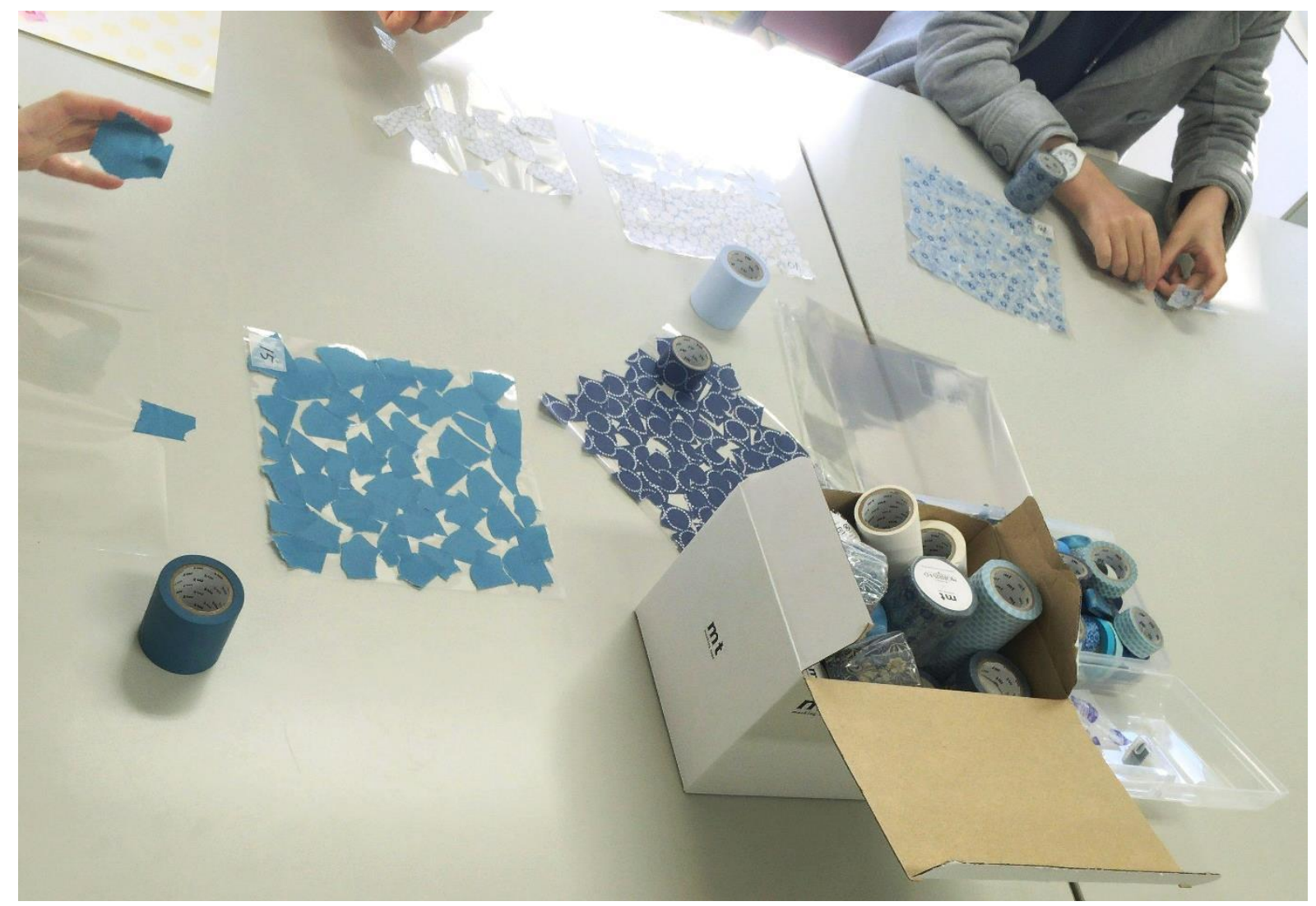

Fig 1:

Attaching masking tapes to thin film sheets 


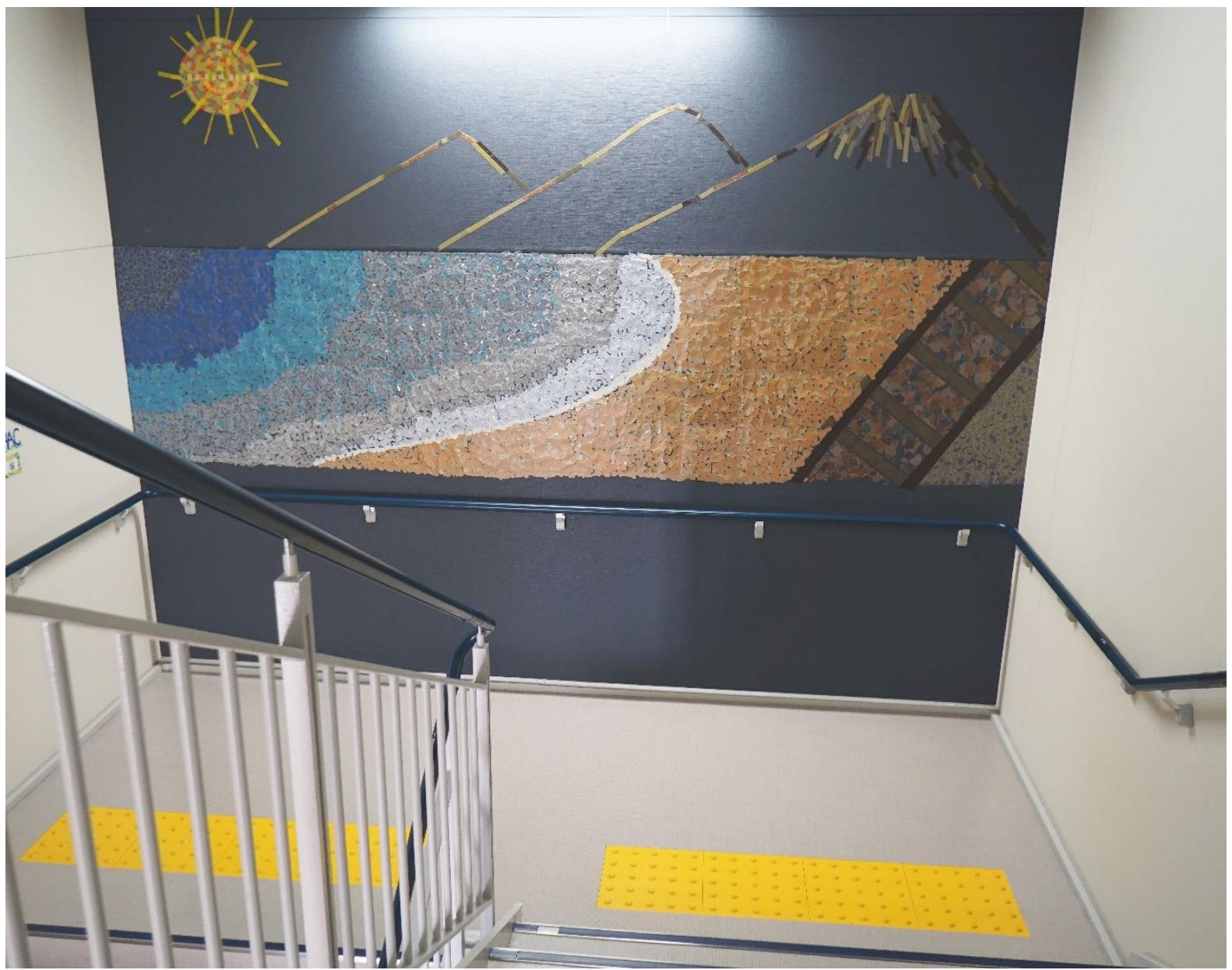

Fig 2:

Art work on the corridor of Minami Hospital, The design is from Tai-no-hama beach, nearby Minami Hospital, Tokushima, Japan

was difficult for elderly people in wheelchairs to put masking tape directly on the wall. We thought of a way to create a mural painting that they could work on safely at the tables, and that another person could install on the wall what they created. This time, we applied this method to prepare the parts of the work outside the hospital and quickly put them on the wall at the site. As a result, we could complete the work in the waiting room and on the stair landing in just three working sessions (Fig-2).

As mentioned above, we have created an idea that utilizes film sheets in the activities of hospital art. The presence of art in the hospital can provide beneficial feelings to patients and staff [12]. By applying the current working method using thin film sheets, we could create hospital art in a short time and safely, even under difficult circumstances. The satisfaction of those related to our work was very high. They say that looking at the artworks can calm them down. This method of combining masking tape and thin film sheets to create artwork is expected to become an effective way to support medical staff and patients from outside the hospital in the future.

\section{Conflict of Interest}

The authors have read and approved the final version of the manuscript. The authors have no conflicts of interest to declare.

\section{References}

[1] Timonen K, Timonen T. Art as contextual element in improving hospital patients' well-being: A scoping review. J Applied Arts Health. 2021;12(2):177-91.

[2] Jones P. The arts therapies: a revolution in healthcare. 2nd Ed. New York: Routledge publishing; 2020. Available from: 
https://www.routledge.com/The-Arts-Therapies-ARevolution-in-

Healthcare/Jones/p/book/9781138651319

[3] Tanaka K, Nagahiro S, Bando H. Beneficial Art in Hospitals with Masking Tape Initiated from University Hospital. Asp Biomed Clin Case Rep. 2020 Sept 05;3(3):202-05.

[4] Kamoi company: masking tape (mt). Available from:

https://www.kamoi-net.co.jp/product/index.html

[5] Tanaka K, Nagahiro S, Bando H. Psychologically comfortable seasonal images for the project on the art in hospitals. Art Human Open Acc J. 2020 Sept 24;4(5):187-189.

[6] Nagahiro S, Tanaka K, Bando H, Bando M, Nakanishi M, Goto S. Masking tape art-work may provide beneficial positive effects. Edel J Biomed Res Rev. 2021 Feb 18;3(1):5-8.

[7] Forgeard M, Silverman A, Buchholz J, Beard C, Björgvinsson T. Changes in general self-efficacy and mindfulness are associated with short-term improvements in mood during art-making in a partial hospital program. The Arts in Psychotherapy.
2021;74:101799.

[8] Bando H. Risk Factors Leading to the Severe Exacerbation of COVID-19 Include Male, Elderly, Obesity and Diabetes. Int J Endocrinol Diabetes. 2021 Oct 1;4(1):120.

[9] Lefèvre H, Stheneur C, Cardin C, Fourcade L, Fourmaux C, Tordjman E, Touati M, Voisard F, Minassian S, Chaste P, Moro MR, Lachal J. The Bulle: Support and Prevention of Psychological Decompensation of Health Care Workers During the Trauma of the COVID-19 Epidemic. J Pain Symptom Manage. 2021 Feb;61(2):416-22. [PMID: 32961219]

[10] Mulligan CB. The backward art of slowing the spread? Congregation efficiencies during COVID-19. United States: National Bureau of Economic Research; 2021 May 3. Available from: https://www.nber.org/papers/w28737

[11] Lancaster LC. Mortars and plasters-How mortars were made. The literary sources. Archaeol Anthropol Sci. 2021 Oct 12;13:192.

[12] Bates V. 'Humanizing' healthcare environments: architecture, art and design in modern hospitals. Design Health (Abingdon). 2018 Feb 15;2(1):5-19. [PMID: 30009280] 